\title{
Inovasi Pelayanan Permohonan Pengajuan Izin Dinas Penanaman Modal dan Pelayanan Terpadu Satu PINTU (DPMPTSP) Kota SAMARINDA
}

jurnal.kemendagri.go.id/index.php/ $\mathrm{mp}$

\section{e-ISSN: 2549-5283}

p-ISSN: 2549-5151

Matra Pembaruan 4 (2) (2020): 135145

DOI:-

10.21787/mp.4.2.2020.135-145

Keywords: Digital Literacy, Public Service, Innovation, DPMPTSP,

Samarinda

Kata Kunci: literasi digital, pelayanan publik, inovasi, DPMPTSP Samarinda

\section{*Korespondensi \\ Phone : +6281 1556776 \\ Email : bambangirawan@unmul. ac.id}

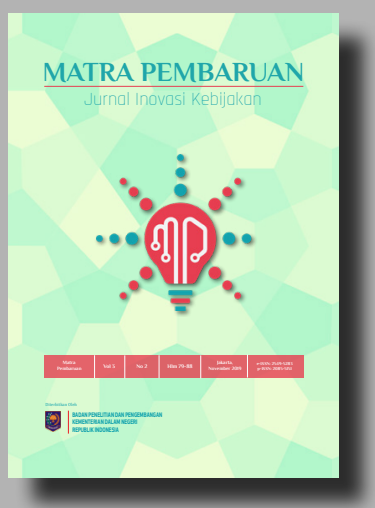

BADAN PENELITIAN DAN PENGEMBANGAN (BPP) KEMENTERIAN DALAM NEGERI

Jl. Kramat Raya No 132, Jakarta Pusat, 10450

(C)2020 Bambang Irawan, Muhammad Nizar Hidayat, Paisal Akbar, Andi Hafidz Khanz

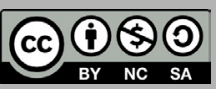

Karya ini dilisensikan di bawah Lisensi Internasional Creative Commons Atribusi Nonkomersial Sharealike 4.0 .

\author{
Bambang Irawan $^{1^{*}}$, Muhammad Nizar Hidayat ${ }^{2}$, \\ Paisal Akbar ${ }^{3}$, Andi Hafidz Khanz ${ }^{4}$ \\ 1,2,4Fakultas Ilmu Sosial dan Ilmu Politik, Universitas Mulawarman, \\ Samarinda. \\ ${ }^{3}$ Program Magister Ilmu Pemerintahan, Universitas \\ Muhammadiyah, Yogyakarta.
}

Dikirim: 25 September 2020; Direvisi: 24 November 2020;

Disetujui: 24 November 2020

\begin{abstract}
The advancement of technology and its utilization by the government in delivering public services does not necessarily correlate with the higher utilization by the citizens as users. Many factors cause it, and one of them is the digital divide among citizens and low digital literacy. The same situation is faced by Investment and One-Stop Services Agency of Samarinda (Dinas Penanaman Modal dan Pelayanan Terpadu Satu Pintu (DPMPTSP) Kota Samarinda), where the citizen does not effectively use several of its online services. Against that backdrop, DPMPTSP tries to innovate on the case with a video assistance tutorial that serves as a visual guideline for the citizens who wish to apply for public services. This article tries to describe the innovation made by DPTMPTSP in order to reduce the gap between digital literacy and e-government program. Using descriptive qualitative methods, this article finds that the implementation of this innovation started with problem identification. Then video assistance tutorial is created based on the identification, and the last stage is to attach a video assistance tutorial on the official sites of DPMPTSP. The video content consists of a cover page of type of service, information on required documents, tutorials to create an account, tutorials on selecting services, tutorials to log in to the portal, tutorials to fill online forms, and tutorials to upload the documents. Besides that, this video is also supplemented with text and audio to help users who might need it. This innovation from DPMPTSP is an effort to increase the digital literacy of Samarinda citizens that can also contribute to e-government services' success.
\end{abstract}

\section{Intisari}

Salah satu aspek yang penting dalam kajian e-government berkaitan dengan peran manusia sebagai pengguna (users) dari teknologi. Kecanggihan teknologi maupun tingginya kualitas teknologi pemerintah ternyata tidak menjamin bahwa instrumen tersebut akan digunakan oleh masyarakat sebagai users. Banyak faktor yang menyebabkan hal tersebut salahsatunya adalah adanya kesenjangan digital (digital divide) dan rendahnya literasi digital (digital literacy) di antara masyarakat. Hal yang sama juga dialami oleh Dinas Penanaman Modal dan Pelayanan Terpadu Satu Pintu (DPMPTSP) Kota Samarinda di mana masyarakat belum maksimal dalam memanfaatkan pelayanan daring yang disediakan. Untuk itu Dinas Penanaman Modal dan Pelayanan Terpadu Satu Pintu (DPMPTSP) Kota Samarinda berinovasi dengan menggunakan media video tutorial dalam pelayanan permohonan izin berbasis daring. Artikel ini bertujuan untuk mendeskripsikan inovasi yang dilakukan oleh DPMPTSP tersebut. Dengan menggunakan metode deskriptif kualitatif, ditemukan bahwa dalam pelaksanaannya identifikasi permasalahan terlebih dahulu dilakukan kemudian dilanjutkan dengan pembuatan video tutorial dan diakhiri dengan penyematan video tutorial ke laman resmi DPMPTSP Kota 
Samarinda. Konten dari video tutorial tersebut antara lain cover depan yang berisikan informasi terkait judul video tutorial, informasi terkait berkas persyaratan, tahapan dalam pembuatan akun, tahapan pemilihan kategori perizinan, tahapan login akun ke portal DPMPTSP, tahapan pengisian borang formulir permohonan, dan tahapan unggah berkas/dokumen persyaratan. Selain itu video tutorial ini juga disertai dengan teks dan audio pendukung yang bertujuan untuk lebih memudahkan pengguna/masyarakat. Inovasi DPMPTSP Kota Samarinda ini merupakan upaya untuk meningkatkan digital literacy masyarakat Kota Samarinda yang sekaligus berimplikasi positif dalam peningkatan penggunaan pelayanan daring yang disediakan.

\section{Pendahuluan}

Perkembangan teknologi dan informasi telah berpengaruh pada seluruh bidang kehidupan manusia tidak terkecuali pada bidang pemerintahan (Distel, 2018). Dengan diadopsinya teknologi informasi ke dalam proses pemerintahan maka istilah electronic government pun muncul menjadi tren baru di abad 21 (Rana et al., 2017). Ide yang mendasari e-government sebenarnya erat dengan prinsip-prinsip demokrasi. e-government merupakan bagian yang tidak terpisahkan dari tata pemerintahan yang baik (Good Governance) yang bertujuan untuk menciptakan pemerintahan transparan, akuntabel, efektif dan memperhatikan aspek kesetaraan (Jameel et al., 2019; United Nations, 2008).

Sebagai konsekuensi dari signifikansi peran e-government dalam pemerintahan, maka tidak heran jika agenda riset dalam subjek akademik terkait memusatkan fokusnya pada kajian e-government menjadi salah satu yang sering dikaji, salah satunya adalah dalam bidangilmu Administrasi Publik yang telah banyak menghasilkan sub-kajian e-government dalam kerangka literatur Administrasi Publik dan ilmu-ilmu serumpun lainnya seperti kajian mengenai faktor-faktor yang menentukan keberhasilan implementasi e-government (GilGarcía \& Pardo, 2005). Pembahasan tentang konsep serta teori e-government itu sendiri sampai pada perbandingan penerapannya di berbagai Negara seperti pada Negara berkembang dan Negara maju (Aladwani, 2016; Choi et al., 2016; Elkadi, 2013; Guijarro, 2007; Salsabila \& Purnomo, 2017; Schuppan, 2009; Veeramootoo et al., 2018).

Aspek yang juga penting dalam kajian e-government berkaitan dengan manusia sebagai pengguna (users) dari teknologi (Rana dkk., 2017). Bahkan barangkali aspek ini adalah aspek yang lebih penting karena keseluruhan upaya untuk memperbaiki kualitas dan teknologi tidak akan banyak berguna apabila penggunanya tidak mau/ mampu untuk menggunakan instrumen tersebut (Al-Naimat et al., 2013). Kecanggihan teknologi maupun tingginya kualitas teknologi pemerintah ternyata tidak menjamin bahwa instrumen tersebut akan digunakan oleh masyarakat sebagai users. Banyak sekali faktor yang membuat masyarakat tidak mau/mampu untuk mengakses serta mengoperasionalisasikan instrumen e-government resmi yang disediakan oleh pemerintah salahsatunya adalah terjadinya kesenjangan digital (digital divide) (Lee et al., 2020).

Konsep digital divide atau kesenjangan digital merujuk pada pemahaman terkait akses yang tidak sama terhadap teknologi informasi dan adanya kesenjangan kemampuan yang dibutuhkan untuk menggunakan teknologi informasi (Pérez-Morote et al., 2020; Suwana \& Lily, 2017). Konsep ini memiliki kaitan erat dengan konsep lain yakni information literacy (literasi informasi) atau digital literacy yang didefinisikan sebagai kapasitas seseorang untuk menggunakan teknologi informasi dan komunikasi berbasis digital sebagai alat untuk mencapai tujuan baik itu tujuan personal maupun professional (Lee dkk., 2020).

Konsep digitaldivide dan digitalliteracymenjadi titik permasalahan ketika hal tersebut berimplikasi langsung terhadap keberhasilan program e-government baik di lingkungan pemerintah pusat sampai dengan pemerintah daerah. Tidak terlepas dari hal tersebut, permasalahan yang sama juga terjadi pada lingkungan pemerintah Kota Samarinda, hal ini terlihat dari rendahnya tingkat digital literacy yang dimiliki. Pernyataan ini bisa dideduksi dari hasil riset secara nasional yang mengatakan bahwa digital divide dan digital literacy di Indonesia masih menjadi masalah besar bahkan di Pulau Jawa yang notabene merupakan pusat pembangunan (Sujarwoto \& Tampubolon, 2016). Memang apabila dilihat secara sekilas tren penggunaan gawai dan medium elektronik yang berbasis digital serta terkoneksi dengan internet mengalami peningkatan. Namun tidak sertamerta hal ini berbanding lurus dengan tingkat literasi informasi yang dimiliki (Eshet-Alkalai, 2004).

Permasalahan ini tentu saja membutuhkan langkah-langkah strategis yang ditujukan untuk menjembatani antara rendahnya tingkat digital literacy masyarakat dengan tujuan e-government. Dengan demikian maka dibutuhkan suatu inovasi yang tepat dan efektif sebagai solusi dari permasalahan tersebut.

Oleh karenanya inovasi pelayanan yang berlandaskan pada semangat penanggulangan digitaldivide diperlukan dalam rangka meningkatkan keefektifan sebuah layanan yang tersedia, untuk itulah diperlukan sebuah perubahan dalam hal cara sebuah layanan berkomunikasi dengan penggunannya dan kehadiran internet menjadi salah satu aspek penting untuk mewujudkan pola komunikasi yang efektif (Kosasih, 2016).

Inovasi pelayanan dalam konteks ini lebih ditujukan pada upaya-upaya yang dilakukan oleh pemerintah dalam mengatasi permasalahan 
kesenjangan digital dan literasi digital yang rendah pada masyarakat. Inovasipelayanan publik ditujukan untuk memaksimalkan peran teknologi informasi namun di sisi lainnya tetap memperhatikan dimensi accessibility atau aksesibilitas dari teknologi tersebut. Mengapa ini penting? Sebagaimana yang telah disinggung sebelumnya, bahwa kemajuan teknologi informasi dan kecanggihan inovasi pelayanan yang telah dibuat oleh pemerintah daerah tidak akan berarti banyak apabila masyarakat tidak bisa mengakses layanan tersebut misalnya dalam konteks ini disebabkan oleh rendahnya literasi digital yang mereka miliki. Maka dari itu inovasi yang dilakukan oleh Pemerintah Kota Samarinda khususnya Dinas Penanaman Modal dan Pelayanan Terpadu Satu Pintu (DPMPTSP) dalam konteks ini adalah inovasi yang ditujukan untuk membantu masyarakat agar dapat mengakses layanan publik yang dikembangkan dengan berbasis Teknologi Informasi seperti Pelayanan Perizinan secara daring.

Penelitian-penelitian terdahulu dalam bidang inovasi pelayanan telah banyak di lakukan. Pertama penelitian yang dilakukan oleh Atthahara (2018) yang meneliti tentang inovasi pelayanan Dinas Komunikasi dan Informatika di Kabupaten Purwakarta yang meluncurkan aplikasi layanan Ogan Lopian, aplikasi Ogan Lopian ditujukan dalam memberikan kemudahan akses pelayanan bagi masyarakat di bidang laporan pengaduan, kesehatan, keamanan, serta lowongan pekerjaan (Atthahara, 2018). Kedua, adalah penelitian dari Ikhsani dan Rifki (2017) terkait inovasi tata kelola Izin Mendirikan Bangunan (IMB) di Kota Pontianak. Inovasi yang dilakukan Pemerintah Kota Pontianak berhasil secara efektif dalam mengurangi waktu penyelesaian izin yang bisa selesai dalam satu hari.

Ketiga, penelitian tentang inovasi pelayanan juga dilakukan oleh Muharam \& Melawati (2019) di Kota Bandung, inovasi pelayanan yang ada di Kota Bandung memberikan beragam model inovasi pelayanan yang berbasiskan semangat era revolusi industri 4.0 (Muharam \& Melawati, 2019). Keempat, penelitian oleh Sari (2019) yang berkaitan dengan inovasi manajemen retribusi pasar di Kota Surakarta. Hasil penelitian Sari menunjukkan bahwa inovasi yang dilakukan mempermudah pengelolaan retribusi pasar secara cepat, efektif dan efisien dibandingkan dengan cara konvensional (Sari, 2019).

Kelima, Inovasi pelayanan juga dilakukan dalam bidang pelayanan transportasi publik yang dimiliki Kota Malang dengan meluncurkan berbagai macam layanan publik di Stasiun Malang guna untuk menjawab kebutuhan masyarakat dan memberikan efektivitas dan efisiensi dalam memberikan pelayananan (Nasikhah, 2019). Keenam, adalah penelitian Sofianto (2019) tentang inovasi manajemen pemerintahan berbasis aplikasi digital di Provinsi Jawa Tengah. Sofianto menemukan bahwa inovasi ini masih menghadapi permasalahan besar salah satunya adalah kurangnya kesiapan pengguna dan belum adanya sinkronisasi antar aplikasi yang dikembangkan (Sofianto, 2019).

Ketujuh, inovasi pelayanan juga tidak hanya terjadi di tingkatan kabupaten/kota namun juga terjadi di tingkatan desa, Nursetiawan (2018) dalam penelitiannya mengemukakan inovasi pelayanan juga harus hadir di tingkat desa yang dalam hal ini diwujudkan di ranah Badan Usaha Milik Desa (BUMDes), BUMDes harus mampu untuk membaca potensi ekonomi, potensi sosial, potensi Sumber Daya Manusia (SDM) yang dimiliki desa sehingga dapat memberikan kesejahteraan ekonomi bagi masyarakat desa yang memiliki permasalahan dalam perekonomian (Nursetiawan, 2018).

Dari beberapa penelitian tersebut, kasus yang diangkat dalam penelitian kali ini dan menjadi pembeda dari penelitian-penelitian sebelumnya yaitu upaya inovasi pelayanan Pemerintah Daerah Kota Samarinda melalui Dinas Penanaman Modal dan Pelayanan Terpadu Satu Pintu (DPMPTSP) dalam memberikan pelayanan permohonan izin berbasis daring dengan menggunakan media video tutorial cara pengisian permohonan izin. Seperti yang disampaikan Nedungadi dkk, (2018) penggunaan video tutorial ini salah satunya diharapkan mampu untuk meningkatkan tingkat digital literacy masyarakat, dalam hal ini video tutorial ditujukan untuk meningkatkan digital literacy masyarakat Samarinda, khususnya bagi pengguna layanan tersebut. Sebelumnya proses edukasi dan pemberian informasi tahapan cara pengisian permohonan izin berbasis daring hanya disediakan melalui file PDF pedoman petunjuk pengisian. Penggunaan video tutorial pelayanan izin di DPMPTSP Kota Samarinda ini juga menjadi yang pertama kalinya di lingkungan Kota Samarinda. Video tutorial ini merupakan upaya dari DPMPTSP Kota Samarinda untuk menjembatani digital literacy masyarakat yang rendah dengan sarana e-government yang telah disediakan. Diharapkan video tutorial yang disiapkan bisa membuat masyarakat Samarinda bisa menggunakan layanan daring secara maksimal.

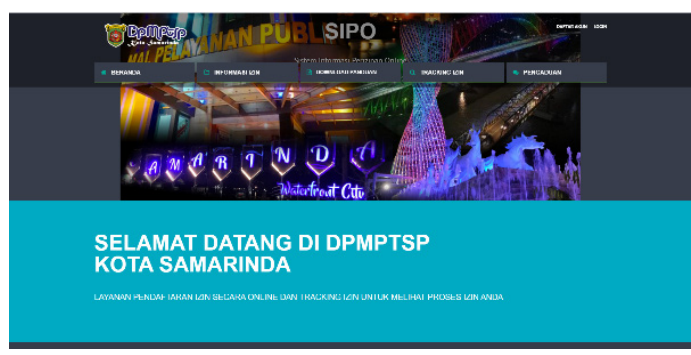

Gambar 1.

Tampilan Laman Portal Pelayanan Izin Daring DPMPTS Kota Samarinda

Sumber: (DPMPTS Kota Samarinda, 2020) 
Inovasi tersebut sebenarnya memiliki tujuan untuk mempermudah masyarakat yang ingin mengurus izin secara daring sehingga tidak perlu lagi menyertakan bukti berkas fisik dalam pemprosesannya. Dalam prakteknya masyarakat hanya perlu untuk mengisi formulir secara daring serta mengunggah berkas-berkas persayaratan ke laman DPMPTSP yang telah tersedia. Panduan penggunaan serta pengisian formulir juga telah disiapkan oleh pihak DPMPTS dalam bentuk PDF yang bisa diunduh di laman yang sama. Meski demikian penggunaan instumen perizinan online ini masih belum maksimal. Hal ini dikarenakan keterbatasan akses pengguna terhadap layanan daring yang tersedia serta kurangnya pemahaman penyelenggara pelayanan publik khususnya di Kota Samarinda dalam memaksimalkan inovasi dalam penggunaan platform daring.

Masyarakat Samarinda memiliki kesulitan dalam mengisi formulir secara daring serta menggunggah berkas-berkas yang diperlukan. Bahkan dalam beberapa kasus mereka belum mampu untuk merubah berkas fisik/hardcopy menjadi berkas softcopy, selain itu masyarakat Kota Samarinda belum terbiasa dalam menggunakan instrumen formulir daring meskipun sudah disediakan panduan secara tertulis di laman portal pelayanan DPMPTSP. Oleh karenanya untuk meningkatkan kualitas pelayanannya diperlukan panduan video tutorial agar dapat semakin meningkatkan literacy dan pemahaman masyarakat terhadap pelayanan yang disediakan pada laman website-nya yaitu menyediakan video tutorial paket perizinan online yang dapat digunakan oleh pemohon sebagai panduan ketika melakukan prosedur layanan. Hal tersebut sejalan dengan salah satu rekomendasi dari hasil penelitian yang dilakukan oleh (Wahyu p, 2016).

Berdasarkan penjelasan di atas maka artikel ini berupaya untuk memberikan deskripsi dari proses hadirnya sebuah solusi terhadap permasalahan yang dihadapi oleh DPMPTSP yakni dengan membuat video tutorial atau assistance video yang bertujuan untuk memudahkan masyarakat dalam menggunakan instrumen formulir daring dan menikmati pelayanan yang tersedia di dalam laman portalnya.

\section{Metode}

Tahapan awal yang ditempuh untuk melaksanakan penelitian terhadap permasalahan yang terjadi di DPMPTSP Kota Samarinda dapat dilihat dalam tabel berikut:
Tabel 1.

Tahapan dan Langkah Kerja

\begin{tabular}{cl}
\hline No & \multicolumn{1}{c}{ Langkah Kerja } \\
\hline 1 & $\begin{array}{l}\text { Identifikasi permasalahan dalam pengajuan } \\
\text { permohonan perizinan daring di kantor DPMPTSP } \\
\text { Kota Samarinda melalui wawancara bersama } \\
\text { Kepala Seksi Pengolahan Data, Bapak Syafrilian } \\
\text { Apri, ST }\end{array}$ \\
\hline 3 & $\begin{array}{l}\text { Verifikasi langsung ke laman portal DPMPTS } \\
\text { gori untuk dibuatkan video tutorial }\end{array}$ \\
\hline 4 & $\begin{array}{l}\text { Pembuatan bahan mentah video tutorial menggu- } \\
\text { nakan aplikasi Camtasia }\end{array}$ \\
\hline 5 & $\begin{array}{l}\text { Edit video tutorial dan penambahan teks serta } \\
\text { audio }\end{array}$ \\
\hline 6 & $\begin{array}{l}\text { Revisi konten video tutorial dari berbagai pihak } \\
\text { laman portal DPMPTSP Kota Samarinda }\end{array}$ \\
\hline
\end{tabular}

Sumber: diolah oleh penulis

Penelitian ini menggunakan metode kualitatif deskriptif dengan menitikberatkan pada informasi dan deskripsi yang bersifat naratif dan mendeskripsikan fenomena yang diteliti. Selain itu, penelitian kualitatif dapat diartikan sebagai upaya untuk memberikan makna terhadap fenomena berdasarkan data yang diperoleh. (Sugiyono, 2017) Oleh karena itu, maka tahapan yang pertama dilakukan adalah identifikasi permasalahan yang dihadapi oleh DPMPTSP Kota Samarinda. Hal ini dilakukan dengan cara wawancara yang intensif bersama narasumber guna untuk mengetahui kebutuhan daripada masyarakat dalam penggunaan laman portal DPMPTSP. Sedangkan partisipasi mitra di sini adalah memberikan feedback terhadap serangkaian kegiatan identifikasi yang telah dilakukan sebagai bahan masukan dan perbaikan bagi video tutorial yang dibuat.

\section{HASIL DAN PEMBAHASAN}

\section{A. Identifikasi Masalah Layanan}

Dalam upaya menghadirkan inovasi pelayanan di DPMPTSP Kota Samarinda proses diawali daripada upaya untuk mengidentifikasi masalah yang dihadapi portal laman Permohonan Pengajuan Izin DPMPTSP. Berdasarkan hasil wawancara baik dengan masyarakat pengguna layanan dan aparat pengolahan data DPMPTSP Kota Samarnda ditemukan beberapa kendala yang membuat rendahnya penggunaan layanan izin daring yakni: 
Tabel 2.

Indentifikasi Permasalahan

\begin{tabular}{cl}
\hline No & \multicolumn{1}{c}{ Permasalahan yang ditemukan } \\
\hline 1 & $\begin{array}{l}\text { Rendahnya kemampuan masyarakat (digital liter- } \\
\text { acy) dalam mengoperasikan fitur-fitur daring. }\end{array}$ \\
\hline 2 & Panduan tertulis yang tersedia tidak efektif. \\
\hline 3 & $\begin{array}{l}\text { Tidak semua jenis layanan yang tersedia digu- } \\
\text { nakan dengan maksimal oleh masyarakat. }\end{array}$ \\
\hline
\end{tabular}

Sumber: diolah oleh penulis dari hasil wawancara

Permasalahan utama yang dihadapi adalah rendahnya kemampuan masyarakat dalam mengoperasikan fitur-fitur daring. Kendala ini menunjukkan bahwa tingkat literasi digital masyarakat Kota Samarinda masih belum cukup tinggi untuk menggunakan fitur-fitur pelayanan daring yang telah disediakan. Hal ini dikonfirmasi oleh narasumber penelitian yang sekaligus menjabat sebagai Kasi Pengolahan Data DPMPTSP Kota Samarinda yang mendeksripsikan bahwa permohonan perizinan yang masuk masih belum optimal dan dari permohonan yang masuk ke dalam database atau server DPMPTS cukup banyak yang terkendala dengan isian formulir yang keliru serta unggahan dokumen yang kurang ideal seperti salah unggah atau unggahan yang tidak bisa terbaca di server DPMPTSP (Irawan dkk., 2020).

Sebenarnya dari pihak DPMPTS Kota Samarinda telah memberikan panduan terkait bagaimana tata cara pengisian formulir dan unggah berkas di portal permohonan perizinan daring yang tersedia dalam bentuk tertulis atau PDF serta bisa diunduh pada laman portal. Meski demikan agaknya panduan tertulis tersebut belum cukup banyak membantu masyarakat atau pemohon dalam pengoperasian permohonan perizinan daring. Kurang optimalnya panduan tertulis yang disediakan oleh DPMPTS agaknya bukan disebabkan dari kurang lengkapnya informasi yang dicantumkan dalam panduan tersebut, bahkan hasil observasi dokumen menunjukkan bahwa informasi terkait tahapan-tahapan yang harus dilakukan serta data-data yang harus diisikan dalam formulir daring telah disediakan didalam panduan tertulis.

Setelah dilakukan wawancara terhadap pengguna layanan daring, ditemukan informasi bahwa beberapa dari mereka tidak menemukan tautan untuk mengunduh panduan tertulis. Hal ini memang menjadi kendala tersendiri dikarenakan letak tautan yang tidak berada di halaman depan portal. Selanjutnya dari beberapa pengguna layanan yang berhasil mengunduh panduan tertulis, ditemukan bahwa mereka masih kesulitan dalam memahami instruksi yang didominasi oleh teks. (Irawan et al., 2020a)
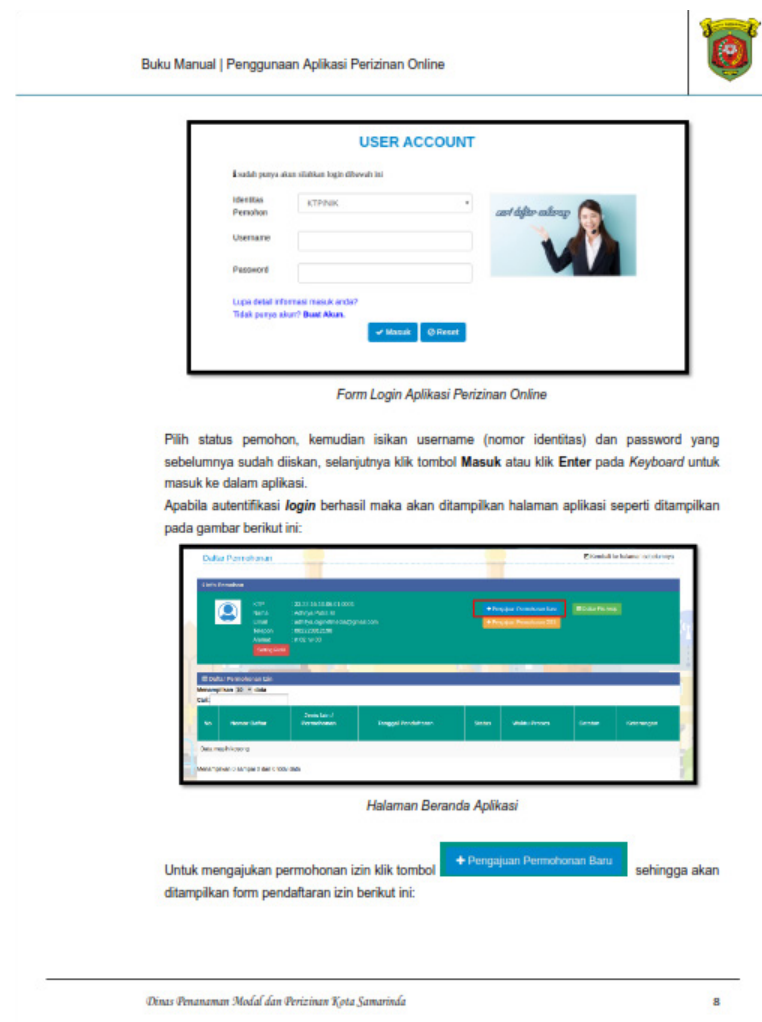

Gambar 2.

Deskripsi Panduan Tertulis Pengisian Pemohonan Izin DPMPTSP Kota Samarinda

Sumber: (DPMPTS Kota Samarinda, 2020)

Selain itu bisa dikatakan pula bahwa kurang efektifnya panduan tertulis pengajuan permohonan perizinan daring yang telah disediakan oleh DPMPTS cenderung disebabkan oleh rendahnya minat baca masyarakat Indonesia secara umum (Setyawatira, 2009; Tahmidaten \& Krismanto, 2020). Budaya baca masyarakat Indonesia masih jauh tertinggal dibandingkan dengan negara ASEAN lainnya, bahkan budaya baca Indonesia masih tergolong sangat rendah (Tahmidaten \& Krismanto, 2020). Data umum ini bisa menjadi acuan asumsi bahwa kondisi yang serupa juga terdapat di Kota Samarinda. Dengan demikian maka tidak mengherankan apabila tingkat literasi digital masyarakat di Kota Samarinda masih sangat kurang karena budaya baca masyarakat yang tidak mendukung.

Dua permasalahan itu bermuara pada kurang maksimalnya penggunaan layanan permohonan perizinan daring yang disediakan oleh DPMPTSP Kota Samarinda. Menurut informasi yang disampaikan oleh narasumber dari DPMPTSP Kota Samarinda bahwa jenis layanan yang paling banyak diakses adalah permohonan praktik perawat baru sedangkan permohonan perizinan daring lainnya kurang dimaksimalkan oleh masyarakat. Bahkan banyak masyarakat yang kemudian masih datang secara langsung ke kantor DPMPTSP untuk 
mengurus perizinan sebagaimana cara konvensional meskipun layanan secara daring sudah disediakan. (Irawan dkk., 2020).

Jika dianalisis secara sederhana bisa didapatkan kesimpulan tentang keterkaitan antara literasi digital pemohon dan tingkat penggunaan layanan perizinan daring. Pengajuan permohonan perizinan praktek perawat baru didominasi oleh lulusan baru (freshgraduate) dari bidang keperawatan yang notabene merupakan generasi milenial yang sudah sangat terbiasa dengan gawai dan serbaserbi teknologi informasi. Sedangkan permohonan perizinan lainnya seperti permohonan perizinan penyimpanan bahan bakar untuk industri ternyata masih kurang banyak digunakan. Berdasarkan keterangan yang diperoleh dari narasumber di DPMPTSP diketahui bahwa kebanyakan praktisi yang berkecimpung dalam usaha penyimpanan bahan bakar industri adalah masyarakat yang termasuk dalam generasi tua (Irawan et al., 2020b). Permasalahan utama yang terdapat pada kelompok usia ini adalah bahwa mereka kurang terbiasa dalam penggunaan gawai serta instrumen daring yang berbasis teknologi informasi. Bahkan dalam beberapa kasus yang terjadi adalah masyarakat atau pemohon masih datang ke kantor DPMPTSP dengan membawa berkas-berkas fisik atau hardcopy untuk mendaftarkan permohonan perizinan usaha mereka. Fakta yang ditemukan ini seakan membuat kebijakan pelayanan permohonan perizinan daring yang disediakan oleh DPMPTSP Kota Samarinda sangat tidak efektif.

Kendala-kendala yang terjadi tersebut menunjukkan bahwa meskipun laman portal pelayanan perizinan DPMPTSP Kota Samarinda telah tersedia dan memiliki panduan tertulis namun tetap saja kemampuan masyarakat untuk menggunakan teknologi tersebut masih sangat rendah (Lee dkk., 2020; Madakam, Ramaswamy, \& Tripathi, 2015). Oleh karena itulah dibutuhkan sebuah inovasi pelayanan yang dapat menjawab permasalahan-permasalahan yang ada, salah satu upaya tersebut adalah dengan menghadirkan video tutorial tahapan pelayanan perizinan yang dapat mempermudah masyarakat dalam memahami langkah demi langkah yang sistematis dalam mengurus perizinan di DPMPTSP Kota Samarinda.

\section{B. Tahap Pembuatan Video Tutorial}

Video tutorial adalah sebuah rangkaian gambar visual yang dapat memberikan pemahaman kepada penonton untuk memahami materi yang tersedia di dalam video tutorial tersebut (Wirasasmita \& Putra, 2018). Video tutorial memiliki kelebihan dalam hal memberikan pengalaman belajar bagi penggunanya, proses memahami dan belajar penggunanya jadi lebih dimudahkan karena tidak hanya di sajikan dalam bentuk gambar bergerak serta teks, atau dalam kata lain pengguna dapat menikmati proses pembelajaran dengan audio dan visual (MacLeod, Storey, \& Bergen, 2015; Ponzanelli dkk., 2019).

Setelah tahapan identifikasi permasalahan dilakukan, selanjutnya memasuki tahapan penyiapan bahan mentah kebutuhan video tutorial. Dalam hal ini aplikasi yang digunakan dalam pembuatan video tutorial Pelayanan Perizinan DPMPTSP adalah aplikasi Camtasia yang berfungsi sebagai aplikasi pengedit dan perekam layar (Dewi et al, 2020; Sulistya, 2018; Wirasasmita \& Putra, 2018). Aplikasi Camtasia merupakan aplikasi pembuat serta pengedit video gratis yang mudah dioperasikan.

Pada tahapan awal pembuatan video tutorial ini pula dibuat akun serta berkas-berkas lainnya yang bersifat dummy atau fiktif untuk di submit ke dalam laman portal DPMPTSP, tentu saja akun serta berkas-berkas dummy ini sudah diverifikasi dan dalam tahap peng-input-annya yang dilakukan dengan terus aktif berkoordinasi langsung kepada bagian Kasi Pengolahan Data DPMPTSP Kota Samarinda sebagai pihak yang bertanggung jawab atas portal layanan. Hal ini diperlukan agar nantinya ketika informasi dari akun dummy ini masuk ke dalam sistem maka sistem tidak serta merta melakukan proses sebagaimana akun yang asli bekerja sehingga didapatkan sebuah tahapan ujicoba diluar tahapan asli yang tersedia. Adapun konten atau isi dari video tutorial ini secara umum adalah:

Tabel 3.

Tata Urutan Isi Video Tutorial

\begin{tabular}{|c|c|}
\hline No & Isi Video \\
\hline 1 & $\begin{array}{l}\text { Cover depan yang berisikan informasi terkait } \\
\text { judul video tutorial dan logo DPMPTSP; }\end{array}$ \\
\hline 2 & $\begin{array}{l}\text { Informasi terkait berkas-berkas apa saja yang } \\
\text { diperlukan untuk proses pengunggahan; }\end{array}$ \\
\hline 3 & $\begin{array}{l}\text { Tahapan-tahapan dalam pembuatan akun } \\
\text { portal DPMPTSP; }\end{array}$ \\
\hline 4 & $\begin{array}{l}\text { Tahapan pemilihan kategori perizinan yang } \\
\text { tersedia; }\end{array}$ \\
\hline 5 & Tahapan login akun ke portal DPMPTSP; \\
\hline 6 & $\begin{array}{l}\text { Tahapan pengisian borang formular permo- } \\
\text { honan perizinan; }\end{array}$ \\
\hline 7 & $\begin{array}{l}\text { Tahapan Unggah berkas/dokumen pers- } \\
\text { yaratan; }\end{array}$ \\
\hline 8 & $\begin{array}{l}\text { Video disertai dengan teks dan audio pen- } \\
\text { dukung. }\end{array}$ \\
\hline
\end{tabular}

Sumber: (Irawan dkk., 2020)

Ditahap penyiapan bahan mentah video tutorial, persiapan dilakukan dengan menggunakan aplikasi perekam dan edit layar Camtasia (Dewi dkk., 2020). Setelah persiapan bahan mentah 
selesai maka selanjutnya adalah proses editing. Dalam proses ini dimasukkan teks pendukung yang berisikan narasi tutorial tahapan bagi pemohon disamping itu pula video ini dilengkapi dengan audio yang direkam melalui voice recorder yang dimaksudkan untuk membantu pemohon yang mengalami keterbatasan dalam memahami alur video. Pada prinsipnya pembuatan video tutorial tersebut berpegangan kepada prinsip aksesibilitas penggunaan e-government, untuk itulah perlu diperhatikan terkait ketersediaan layanan bagi masyarakat yang memiliki keterbatasan baik dalam hal ini buta aksara dan keterbatasan-keterbatasan fisik lainnya (Auditia, 2018).

Untuk itu detail yang terdapat dalam konten video tutorial diperhatikan sedemikian rupa agar video yang dibuat bisa diakses dan bermanfaat bagi masyarakat luas. Latar belakang atau background putih dipilih sebagai warna latar yang memudahkan kontras antara warna huruf (teks) dan gambar. Warna teks narasi dipilih warna gelap yang berkontras baik dengan warna putih sebagai warna latar. Selain itu warna dari konten lain seperti gambar keterangan dan lain sebagainya dipilih dengan mempertimbangkan kontras tersebut. Adapun rasio gambar keterangan yang berfungsi sebagai panduan dibuat dengan rasio yang cukup besar namun proporsional dibandingkan dengan lebar layar yang tersedia. Kemudian fitur audio atau narasi panduan dalam bentuk suara disampaikan dengan intonasi yang jelas serta dengan kecepatan yang dirasa cukup dan tidak terlalu cepat ataupun tidak terlalu lambat. Kombinasi antara kontras layar dan teks serta gambar yang proporsional juga diatur pergerakannya (slide) dengan mempertimbangkan jenis informasi yang ditampilkan dalam layar. Artinya jika informasi yang ingin disampaikan dalam satu frame video dirasa cukup penting maka durasi frame tersebut diatur dengan durasi yang cukup lama dibandingkan dengan frame lainnya. Terakhir, durasi video juga disesuaikan dengan banyak atau tidaknya infromasi terkait dengan permohonan perizinan yang dituju. Secara umum durasi video tutorial yang dibuat berkisar antara tujuh sampai sepuluh menit.

\section{Jenis dan Implikasi Video Tutorial}

Terdapat delapan video tutorial yang dibuat dalam upaya inovasi pelayanan oleh DPMPTSP Kota Samarinda, video tutorial tersebut tersebar dalam delapan kategori perizinan. Meskipun secara keseluruhan total kategori perizinan yang ada di portal DPMPTSP Kota Samarinda berjumlah empat belas buah, namun hanya delapan kategori yang bisa diakses oleh masyarakat.
TPMPËS

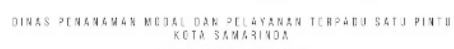

WEMFERSEMESHKAK

\section{PANDUAN PENGISIAN PERMOHONAN IZIN PEMBUANGAN AIR LIMBAH BARU}

Gambar 3.

Tampilan Awal Video Tutorial Panduan Pengisian Pemohonan Izin DPMPTSP Kota Samarinda

Sumber: (DPMPTS Kota Samarinda, 2020)

Sementara itu enam kategori lainnya memiliki kendala masalah kewenangan dalam beberapa layanan perizinan yang tersedia ada yang tidak lagi berada dalam kewenangan pemerintah daerah namun sudah dibawah wewenang pemerintah pusat, sehingga menyebabkan laman kategori perizinan yang tersedia di portal DPMPTSP akan langsung tersambung ke laman perizinan yang tersedia di pemerintah pusat. Masalah kedua adalah permasalahan teknis di level pemerintah daerah Kota Samarinda sendiri yang belum merevisi persyaratan administratif yang diperlukan sehingga informasi terkait persyaratan tidak muncul di laman portal perizinan DPMPTSP Kota Samarinda.

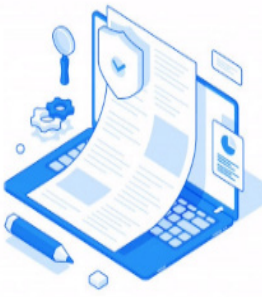

DOKUMEN PERSYARATAN YANG HARUS DISIAPKAN

1. KTP Penanggung Jawab 2. IMB Penumpukan

3. Pas Foto Terbaru Berwarn

4. Rekomendasi Dinas Lingkungan Hidup

Kota Samarinda

"semua dokumen dalam bentuk sofffile

Gambar 4

Informasi Persyaratan Permohonan Perizinan Dalam Video Tutorial

Sumber:(DPMPTS Kota Samarinda, 2020)

Adapun ke delapan jenis perizinan yang telah tersedia di portal DPMPTSP Kota Samarinda dapat dilihat dari tabel di bawah ini:

Tabel 4.

Jenis Perinzinan Pada Portal DPMPTSP Kota Samarinda

\begin{tabular}{cl} 
No & \multicolumn{1}{c}{ Jenis Permohonan Perizinan } \\
\hline 1 & Izin Reklame Tetap \\
\hline 2 & Lembaga Pelatihan Kerja Swasta Baru \\
\hline 3 & $\begin{array}{l}\text { Pengumpulan Uang dan Barang Dalam Wilayah } \\
\text { Kota Samarinda Baru }\end{array}$ \\
\hline 4 & Operasional Pendirian Kelompok Bermain Baru \\
\hline
\end{tabular}




\begin{tabular}{ll}
\hline 5 & Pembuangan Air Limbah Baru \\
\hline 6 & Penyimpanan Bahan Bakar Untuk Industri \\
\hline 7 & Praktek Perawat Baru \\
\hline 8 & SIUPIP Warnet/Internet Baru \\
\hline
\end{tabular}

Sumber: (DPMPTS Kota Samarinda, 2020)

Pada tabel 4 di atas dapat kita lihat terdapat delapan jenis permohonan perizinan yang tersedia di DPMPTSP Kota Samarinda. Jenis Permohonan pertama adalah permohonan perizinan dalam izin reklame tetap, kedua permohonan perizinan lembaga pelatihan kerja swasta baru, ketiga perizinan pengumpulan uang dan barang dalam wilayah Kota Samarinda baru, keempat perizinan operasional pendirian kelompok bermain baru, kelima perizinan pembuangan air limbah baru, keenam perizinan penyimpanan bahan bakar untuk industri, ketujuh perizinan praktek perawat baru, kedelapan perizinan SIUPIP Warnet/Internet baru.

Dari delapan jenis permohonan yang telah memiliki video tutorial tersebut menunjukkan bahwa telah terjadi inovasi pelayanan di DPMPTSP Kota Samarinda yang tadinya petunjuk pengisian perizinan bersifat "manual book" kini telah berinovasi dengan tersedianya fasilitas petunjuk audio visual yang disajikan didalam materi video tutorial. Selain itu hadirnya fasilitas video tutorial tersebut merupakan sebuah upaya dalam meningkatkan tingkat digital literacy masyarakat di Kota Samarinda (Eshet-Alkalai, 2004; Lee dkk., 2020; Nedungadi dkk., 2018)

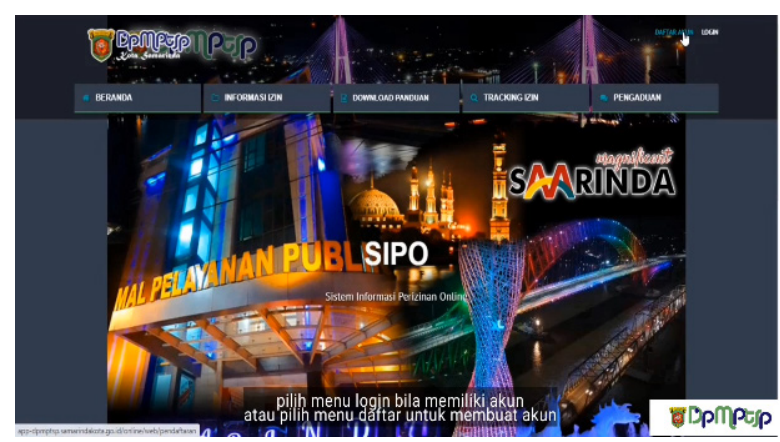

Gambar 5

Narasi Text dan Audio Dalam Video Tutorial Sumber:(DPMPTS Kota Samarinda, 2020)

Inovasi pelayanan publik ialah sebuah upaya untuk memberikan terobosan jenis pelayanan yang ada menjadi lebih kreatif dan bermanfaat. Inovasi pelayanan tidak harus hadir dari penemuan baru tetapi dapat hadir dari pendekatan baru yang sesuai dengan fenomena yang terjadi (Atthahara, 2018). Pendekatan baru yang dimaksud saat ini adalah pendekatan yang dapat mempermudah masyarakat dalam menggunakan fasilitas layanan yang tersedia di portal perizinan DPMPTSP Kota Samarinda.

Memang dalam tahapan identifikasi permasalahan yang dilakukan sebelumnya, ditemukan bahwa kemampuan masyarakat dalam menggunakan fitur-fitur daring masih sangat rendah. Hal ini sebenarnya berkorelasi dengan rendahnya literasi masyarakat di Indonesia dan Samarinda pada khususnya (Setyawatira, 2009; Tahmidaten \& Krismanto, 2020). Literasi yang rendah dalam kasus ini merujuk pada rendahnya minat baca masyarakat. Oleh sebab itu maka tidak mengherankan apabila panduan tertulis terkait penggunaan fitur-fitur daring dalam pelayanan tidak banyak membantu.

Dengan permasalahan tersebut maka DPMPTS berinovasi dengan menggunakan media audio visual yang dilengkapi dengan teks di dalamnya untuk mempermudah masyarakat mendapatkan informasi terkait tahapan pelayanan perizinan daring. Inovasi ini bertujuan untuk mengatasi rendahnya literasi masyarakat dengan menggantinya dengan bentuk visual namun tetap dilengkapi dengan teks sebagai penunjang yang melengkapi penyampaian informasi. Selain itu video ini juga dilengkapi dengan audio yang memandu pemohon atau masyarakat yang menggunakan pelayanan daring, hal ini ditujukan agar video tutorial ini bisa dijangkau serta digunakan oleh masyarakat luas terlepas dari keterbatasan yang mereka miliki.

Sebagaimana yang telah disinggung sebelumnya, bagi generasi milenial yang terbiasa dengan penggunaan gawai serta teknologi informasi maka instrumen permohonan perizinan daring ini tidak menjadi masalah besar bagi mereka, namun lain halnya dengan generasi yang lebih tua. Permasalahannya adalah dalam beberapa pelayanan perizinan yang disediakan, para praktisi atau yang berprofesi dalam jenisjenis usaha tersebut rata-rata berasal dari mereka yang tergolong dalam generasi tua, seperti usaha penyimpanan bahan bakar industri (Irawan dkk., 2020). Permasalahan yang terdapat pada kelompok usia tersebut adalah kurang terbiasanya mereka terhadap penggunaaan teknologi informasi serta fitur-fitur yang menyertainya seperti instrumen permohonan perizinan daring yang disediakan oleh DPMPTSP Kota Samarinda.

Kesenjangan digital (digital divide) penggunaan diharapkan juga dapat lebih teratasi melalui video tutorial yang telah tersedia di DPMPTSP Kota Samarinda (Lee dkk., 2020; Pérez-Morote dkk, 2020; Suwana \& Lily, 2017). Sebagaimana yang telah ditunjukkan oleh beberapa penelitian terdahulu terkait dengan efektivitas video tutorial/video assistance dalam membantu penyelesaian suatu tugas (dalam konteks kali ini adalah penggunaan pelayanan permohonan izin daring), memang terdapat keuntungan atau benefit dalam penggunaan video tutorial, salah satunya adalah mempercepat dan memperjelas komunikasi 
yang diperlukan untuk penyelesaian suatu tugas (Bowles-Terry et al, 2010; Meij, 2017).

Selain itu dengan hadirnya inovasi pelayanan diharapkan pula kepercayaan masyarakat Kota Samarinda terhadap e-government dapat lebih meningkat, inovasi pelayanan e-govenrment dapat menjembatani kepercayaan publik kepada penggunaan e-government (Gil-García \& Pardo, 2005; Jameel dkk., 2019; Mensah, Vera, \& Mi, 2018; Nulhusna, Sandhyaduhita, Hidayanto, \& Phusavat, 2017; Nurmandi \& Purnomo, 2011; Salsabila \& Purnomo, 2017; Sutaryo, Maret, \& Control, 2017; Welch, Hinnant, \& Moon, 2005).

\section{KESIMPULAN}

Harus diakui bahwa masih terdapat jarak antara cita-cita e-government dengan kondisi sosial demografis masyarakat di Indonesia. Jarak inilah yang membuat implementasi program e-government masih tersendat. Sebagaimana di Kota Samarinda, DPMPTSP Kota Samarinda sudah menyediakan terobosan dalam hal pelayanan permohonan perizinan secara daring. Meski demikian digital literacy masyarakat yang masih kurang menjadi kendala dalam pemanfaatan layanan tersebut secara maksimal.

Berbekal identifikasi permasalahan yang telah dikumpulkan dari pihak DPMPTSP dan masyarakat pengguna layanan ditemukan bahwa instruksi penggunaan layanan daring yang telah disediakan oleh DPMPTSP di portal mereka ternyata kurang efektif dalam membantu masyarakat secara luas. Oleh sebab itu DPMPTSP Kota Samarinda melakukan inovasi dalam bentuk penggunaan video tutorial yang memuat instruksi audio visual yang juga dilengkapi dengan teks penjelas.

Diharapkan bahwa video tutorial tersebut mampu untuk menjadi jembatan antara rendahnya digital literacy masyarakat dan program e-government yang berbasis penggunaan teknologi. Hal ini karena berdasakan beberapa studi terdahulu, penggunaan video tutorial atau video assistance ternyata secara efektif bisa membantu penyelesaian suatu tugas tertentu, yang mana dalam konteks kali ini adalah penggunaan pelayanan permohonan perizinan daring.

Penelitian ini juga diharapkan mampu untuk memberikan kontribusi terkait dengan inovasi pelayanan publik khususnya penggunaan video tutorial. Meskipun secara umum penelitian dengan tema yang sama sudah banyak dibuat di tingkat internasional, namun tidak halnya dengan konteks Indonesia. Tema ini perlu untuk mendapatkan perhatian yang serius dikarenakan kondisi sosial demografis masyarakat Indonesia sebagai pengguna teknologi (users) sangat beragam dan memiliki keunikan tersendiri. Sehingga dengan demikian diharapkan penelitian yang dikembangkan bisa menghasilkan suatu khazanah tentang tema video tutorial yang merefleksikan kondisi Indonesia.

Ucapan Terima Kasih

Kami mengucapkan terimakasih kepada pihakpihak yang telah berkontribusi dalam penulisan artikel ini. Pertama adalah Program Studi Magister Administrasi Publik (MAP) Fakultas Ilmu Sosial dan Politik Universitas Mulawarman yang telah berkenan untuk mendanai proyek riset kami. Selain itu terimakasih kami ucapkan kepada Bapak Syafrilian Ardi, ST, Kasi Pengolahan Data DPMPTPS Kota Samarinda sebagai narasumber utama kami yang telah berkenan meluangkan waktu dan berbagi pengalaman terkait dengan inovasi yang diakukan oleh DPMPTSP Kota Samarinda.

\section{Daftar Pustaka}

Al-Naimat, A. M., Abdullah, M. S., \& Ahmad, M. K. (2013). the Critical Success Factors for E-Government Implementation in Jordan. Computing \& Informatics, 4th International Conference, 2013, August, 391-398.

Aladwani, A. M. (2016). Corruption as a source of e-Government projects failure in developing countries: A theoretical exposition. International Journal of Information Management, 36(1), 105-112. https://doi. org/10.1016/j.ijinfomgt.2015.10.005

Atthahara, H. (2018). Inovasi Pelayanan Publik Berbasis E-Government: Studi Kasus Aplikasi Ogan Lopian Dinas Komunikasi dan Informatika di Kabupaten Purwakarta. Jurnal Politikom Indonesiana, 3(1), 66-77. https:// doi.org/10.35706/jpi.v3i1.1412

Auditia, G. G. (2018). E-Government Accessibility for Disability Persons. Inonesian Journal of Disability Studies, 5(2), 185-189. http://dx.doi. org/10.21776/ub.IJDS.2018.005.02.7

Bowles-Terry, M., Hensley, M. K., \& Hinchliffe, L. J. (2010). Best practices for online video tutorials in academic libraries: A study of student preferences and understanding. Communications in Information Literacy, 4(1), 17-28. https://doi.org/10.15760/ comminfolit.2010.4.1.86

Choi, H., Park, M. J., Rho, J. J., \& Zo, H. (2016). Rethinking the assessment of e-government implementation in developing countries from the perspective of the design-reality gap: Applications in the Indonesian e-procurement system. Telecommunications Policy, 40(7), 644-660. https://doi.org/10.1016/j. telpol.2016.03.002

Dewi, N. K. A. P., Adnyani, L. D. S., \& Wahyuni, L. G. E. (2020). Describing Camtasia Video As Learning Media: An Analysis of Response in 
EFL Context. Journal of Education Research and Evaluation, 4(2). https://doi.org/10.23887/ jere.v4i2.24901

Distel, B. (2018). Bringing Light into the Shadows. A Qualitative Interview Study on Citizens' NonAdoption of E-Government. Electronic Journal of E-Government, 16(2), 9.

DPMPTS Kota Samarinda. (2020). Video Assistance Tutorials. DPMPTSP Kota Samarinda.

Elkadi, H. (2013). Success and failure factors for e-government projects: A case from Egypt. Egyptian Informatics Journal, 14(2), 165-173. https://doi.org/10.1016/j.eij.2013.06.002

Eshet-Alkalai, Y. (2004). Digital Literacy: A Conceptual Framework for Survival Skills in the Digital era. Journal of Educational Multimedia and Hypermedia, 13, 93-106.

Gil-García, J. R., \& Pardo, T. A. (2005). E-government success factors: Mapping practical tools to theoretical foundations. Government Information Quarterly, 22(2), 187-216. https://doi.org/10.1016/j.giq.2005.02.001

Guijarro, L. (2007). Interoperability frameworks and enterprise architectures in e-government initiatives in Europe and the United States. Government Information Quarterly, 24(1), 89-101. https://doi.org/10.1016/j. giq.2006.05.003

Ikhsani, E. S., \& Rifki, M. S. (2017). Inovasi Tata Kelola Izin Mendirikan Bangunan di Kota Pontianak. Matra Pembaruan, 1(3), 143-152. https://doi. org/10.21787/mp.1.3.2017.143-152

Irawan, B., Hidayat, M. N., Akbar, P., \& Khanz, A. H. (2020). Wawancara dengan masyarakat pengguna layanan daring DPMPTSP Kota Samarinda.

Jameel, A., Asif, M., \& Hussain, A. (2019). Good governance and public trust: Assessing the mediating effect of E-government in Pakistan. Lex Localis, 17(2), 299-320. https://doi. org/10.4335/17.2.299-320(2019)

Kosasih, I. (2016). Peran Media Sosial Facebook dan Twitter Dalam Membangun Komunikasi (Persepsi dan Motifasi Masyarakat Jejaring Sosial Dalam Pergaulan). Lembaran Masyarakat: Jurnal Pengembangan Masyarakat Islam, 2(1), 29-42. https://doi.org/10.1017/ CB09781107415324.004

Lee, T., Lee, B. K., \& Lee-Geiller, S. (2020). The effects of information literacy on trust in government websites: Evidence from an online experiment. International Journal of Information Management, 52(August 2019). https://doi. org/10.1016/j.ijinfomgt.2020.102098

MacLeod, L., Storey, M. A., \& Bergen, A. (2015). Code, Camera, Action: How Software Developers Document and Share Program Knowledge Using YouTube. IEEE International Conference on Program Comprehension, 2015-Augus, 104114. https://doi.org/10.1109/ICPC.2015.19

Madakam, S., Ramaswamy, R., \& Tripathi, S. (2015). Internet of Things (IoT): A Literature Review. Journal of Computer and Communications, 03(05), 164-173. https://doi.org/10.4236/ jcc.2015.35021

Mensah, I. K., Vera, P., \& Mi, J. (2018). Factors Determining the Use of E-Government Services. International Journal of E-Adoption, 10(2), 1-19. https://doi.org/10.4018/ ijea.2018070101

Muharam, R. S. (2019). Inovasi Pelayanan Publik Dalam Menghadapi Era Revolusi Industri 4.0 Di Kota Bandung. Decision: Jurnal Administrasi Publik, 1(01), 39. https://doi.org/10.23969/ decision.v1i01.1401

Nasikhah, M. A. (2019). Inovasi Pelayanan Transportasi Publik Berbasis Teknologi Informasi. Jurnal Inovasi Ilmu Sosial Dan Politik, 1(1), 26. https://doi.org/10.33474/ jisop.v1i1.2670

Nedungadi, P. P., Menon, R., Gutjahr, G., Erickson, L., \& Raman, R. (2018). Towards an inclusive digital literacy framework for digital India. Education and Training, 60(6), 516-528. https://doi. org/10.1108/ET-03-2018-0061

Nulhusna, R., Sandhyaduhita, P. I., Hidayanto, A. N., \& Phusavat, K. (2017). The relation of e-government quality on public trust and its impact on public participation. Transforming Government: People, Process and Policy, 11(3), 393-418. https://doi.org/10.1108/TG-012017-0004

Nurmandi, A., \& Purnomo, E. P. (2011). Making the strategic plan work in local government: A case study of strategic plan implementation in yogyakarta special province (ysp). International Review of Public Administration, 16(2), 143-164. https://doi.org/10.1080/122 64431.2011.10805200

Nursetiawan, I. (2018). Strategi Pengembangan Desa Mandiri Melalui Inovasi Bumdes. MODERAT: Jurnal Ilmiah Ilmu Pemerintahan, 4(2), 72-81. http://dx.doi.org/10.25147/ moderat.v4i2.1488

Pérez-Morote, R., Pontones-Rosa, C., \& NúñezChicharro, M. (2020). The effects of e-government evaluation, trust and the digital divide in the levels of e-government use in European countries. Technological Forecasting and Social Change, 154(January), 119973. https://doi.org/10.1016/j. techfore.2020.119973

Ponzanelli, L., Bavota, G., Mocci, A., Oliveto, R., Penta, M. DI, Haiduc, S., Russo, B., \& Lanza, M. (2019). Automatic Identification and Classification of Software Development Video Tutorial 
Fragments. IEEE Transactions on Software Engineering, 45(5), 464-488. https://doi. org/10.1109/TSE.2017.2779479

Rana, N. P., Dwivedi, Y. K., Lal, B., Williams, M. D., \& Clement, M. (2017). Citizens' adoption of an electronic government system: towards a unified view. Information Systems Frontiers, 19(3), 549-568. https://doi.org/10.1007/ s10796-015-9613-y

Ratna Sari, Y. (2019). Manajemen Retribusi Pasar Melalui Inovasi Tape Pasar di Kota Surakarta. Matra Pembaruan, 3(1), 13-23. https://doi. org/10.21787/mp.3.1.2019.13-23

Salsabila, L., \& Purnomo, E.P.(2017). Establishing and Implementing Good Practices E-Government (A Case Study : e-Government Implementation between Korea and Indonesia). Asean/ Asia Academic Society International Conference (Aasic), 5(3), 221-229.

Schuppan, T. (2009). E-Government in developing countries: Experiences from sub-Saharan Africa. Government Information Quarterly, 26(1), 118-127. https://doi.org/10.1016/j. giq.2008.01.006

Setyawatira, R. (2009). Kondisi Minat Baca Di Indonesia. Jurnal Media Pustakawan, 16(1 \& 2), 28-33.

Sofianto, A. (2019). Inovasi Manajemen Pemerintahan Berbasis Aplikasi Digital di Provinsi Jawa Tengah. Matra Pembaruan, 3(2), 99-108. https://doi.org/10.21787/ mp.3.2.2019.99-108

Sugiyono. (2017). Metode Penelitian Kualitatif: Untuk Penelitian yang Bersifat: Eksploratif, Enterpretitif, dan Konstruktif. In Alfabeta.

Sujarwoto, S., \& Tampubolon, G. (2016). Spatial inequality and the Internet divide in Indonesia 2010-2012. Telecommunications Policy, 40(7), 602-616. https://doi.org/10.1016/j. telpol.2015.08.008

Sulistya, D. A. (2018). Pengembangan Quantum Teaching Berbasis Video Pembelajaran Camtasia Pada Materi Permukaan Bumi Dan Cuaca. Profesi Pendidikan Dasar, 1(2), 169. https://doi.org/10.23917/ppd.v1i2.5067

Sutaryo, S., Maret, U. S., \& Control, I. (2017). FaktorFaktor Penentu Implementasi E-Government
Pemerintah Daerah Di Indonesia. FaktorFaktor Penentu Implementasi E-Government Pemerintah Daerah Di Indonesia, 5(2), 1393-1408. https://doi.org/10.17509/jrak. v5i2.7931

Suwana, F., \& Lily. (2017). Empowering Indonesian women through building digital media literacy. Kasetsart Journal of Social Sciences, 38(3), 212-217. https://doi.org/10.1016/j. kjss.2016.10.004

Tahmidaten, L., \& Krismanto, W. (2020). Permasalahan Budaya Membaca di Indonesia (Studi Pustaka Tentang Problematika \& Solusinya). Scholaria: Jurnal Pendidikan Dan Kebudayaan, 10(1), 22-33. https://doi. org/10.24246/j.js.2020.v10.11.p22-33

United Nations. (2008). Division for Public Administration, and Development Management. United Nations E-Government Survey, UN.

van der Meij, H. (2017). Reviews in instructional video. Computers and Education, 114, 164-174. https://doi.org/10.1016/j. compedu.2017.07.002

Veeramootoo, N., Nunkoo, R., \& Dwivedi, Y. K. (2018). What determines success of an e-government service? Validation of an integrative model of e-filing continuance usage. Government Information Quarterly, 35(2), 161-174. https://doi.org/10.1016/j.giq.2018.03.004

Wahyu P, E. (2016). Kualitas Pelayanan Paket Perizinan Online Pada Badan Pelayanan Perizinan Terpadu (BPPT) Kabupaten Sidoarjo. Publika, 4(9).

Welch, E. W., Hinnant, C. C., \& Moon, M. J. (2005). Linking citizen satisfaction with e-government and trust in government. Journal of Public Administration Research and Theory, 15(3), 371-391. https://doi.org/10.1093/jopart/ mui021

Wirasasmita, R. H., \& Putra, Y. K. (2018). Pengembangan Media Pembelajaran Video Tutorial Interaktif Menggunakan Aplikasi Camtasia Studio dan Macromedia Flash. Jurnal Pendidikan Informatika, 1(2), 35-43. 